\title{
LA INQUISICIÓN CONTRA LA BIGAMIA: EN DEFENSA DEL ORDEN SOCIAL ${ }^{1}$
}

\author{
José Martínez MiLlán \\ Universidad Autónoma de Madrid - IULCE \\ jose.millan@uam.es
}

$\mathrm{L}$

a bigamia no siempre se ha considerado una acción punible o contraria a las normas sociales. La oposición a nuevas nupcias supuso un fuerte sentido monógamo en la vida colectiva y ello fue debido al decidido empeño por parte de la elite dirigente de mantener cohesionada la sociedad y vinculados los bienes materiales a través del contrato que constituye el matrimonio, concebido como vínculo indisoluble hasta la muerte de uno de los dos cónyuges. Es decir, que el poder temporal estaba tan interesado como la Iglesia en mantener esta unión monógama y en legislar sobre esta vinculación. De la misma manera, vigilaba y castigaba con severidad todas las infracciones cometidas contra esta unión. No resulta extraño que el delito de bigamia constituyera un tema importante para los letrados del Antiguo Régimen y para los historiadores del Derecho actuales.

\section{LA BIGAMIA COMO DELITO EN VARIAS JURISDICCIONES}

Aunque no es mi objetivo ni resulta pertinente realizar un estudio profundo sobre la legislación referente a la bigamia, considero que es necesario tomar conciencia y reflexionar sobre el aspecto legal de este problema para entender el caso que voy a estudiar. Dentro del cuerpo legislativo elaborado dentro de la monarquía hispana,

\footnotetext{
1 Este artículo se ha desarrollado dentro del proyecto «De reinos a naciones. La transformación del sistema cortesano (siglos XVIII-XIX)» (HAR2015-68946-C3-1-P), I+D de Excelencia del Ministerio de Economía y Competividad (MINECO), financiado por la Agencia Estatal de Investigación (AEI) y el Fondo Europeo de Desarrollo Regional (FEDER, UE).
}

Edad de Oro, XXXVIII (2019), pp. 173-196, ISSN: 0212-0429 - ISSNe: 2605-3314

DOI http://doi.org/10.15366/edadoro2019.38.009 
es preciso comenzar recordando que Las Partidas del Rey Sabio ya se ocuparon de la bigamia en el mismo título que sancionaba el adulterio (ley 16, tít. XVII, partida VII, en García Sánchez 2010: 384-386). La pena de destierro que se imponía en Las Partidas a los bígamos se agravó con el paso del tiempo, como se manifiesta en la Nueva Recopilación: Juan I, en las Cortes de Briviesca (1387) ordenó que, además de las penas que en Derecho correspondieran, se marcase la frente de los culpables con un hierro candente la señal de la «q». La mujer siempre fue considerada con una capacidad intelectual de un niño y de débil mental (Gacto Fernández 2013: 28-30; García Gallo 1982: 149-155), lo que suponía (en el Derecho penal) una cierta indulgencia en las penas; esto se mantuvo desde los tiempos de Alfonso $\mathrm{X}$ «el Sabio». La debilidad moral de la mujer, junto con su debilidad física y estrechez intelectual determinó, de manera general, la atenuación de las penas (Lardizábal y Uribe 1782: 117-118; Collantes de Terán de la Hera 2017: 58). En las Cortes de Valladolid de 1548, el emperador Carlos V y su madre, la reina Juana de Castilla, agravaron la pena de destierro, convirtiéndola en cinco años de galeras. Por su parte, Felipe II suprimió la pena de marca de hierro en la frente y la sustituyó por pena de «vergüenza pública y diez años de servicio de galeras» (Nueva Recopilación, lib. VIII, tít. XX, ley 8), castigo que parece se mantuvo durante el siglo XVII. El 5 de febrero de 1770, Carlos III promulgó una cédula en la que secularizó el procedimiento, señalando en Real Orden de 25 de octubre 1777 que «por el mismo hecho de casarse por segunda vez viviendo la primera mujer, se falta a la fe pública del contrato, se engaña a la segunda mujer y ofende a la primera; invierte el orden de la sucesión y de la legitimidad establecida por las leyes civiles». A pesar de su regalismo, el monarca reconocía la intervención de la jurisdicción eclesiástica por constituir una ruptura del sacramento del matrimonio y también admitió que el Santo Oficio pudiera conocer privativamente (Borromeo 1990: 369-374), en cuanto podía tratarse de una herejía, en el sentido luterano, al negar los sacramentos (Nueva Recopilación, lib. XII, lib. 28, ley 10, en Torres Aguilar 1997: 127).

La fundamentación de la jurisdicción eclesiástica sobre el tema de la bigamia se justificó como infracción al sacramento del matrimonio. En el Nuevo Testamento ya se contienen claras recomendaciones que proclaman el matrimonio monogámico. Estas exhortaciones fueron apoyadas y comentadas por los padres de la Iglesia y llegaron a tomar cuerpo canónico en el primer Concilio de Nicea (325), en el que se exigió cumplirlas a todo fiel cristiano, desde donde pasó al Derecho canónico medieval (Droit Canonique 1897: 267). El papa Eugenio, en el decreto Declaramus non solum secundas sed tertias et quartas atque ulteriores, condenaba las segundas nupcias si no existía una certidumbre moral en el sujeto de la disolución del matrimonio precedente, mientras que Lucio III decretó la misma orden en: Auctoritate apostolica respondemus ut nullus ex bobis a modo ad secundas nuptias migrare praesumat donee ei firma certitudine constet quod ab hac 
vita migraverit conjux eius (Valton 1910: 881-885). Con todo, a nivel dogmático, la bigamia fue condenada en el Concilio de Trento en el decreto que dice: «si quis dixerit licere Christianis plures simul habere uxores et hoc nulla lege divina esse prohibitum, Anathema sit».

Durante la primera mitad del siglo Xvi surgió la reforma protestante y Lutero negó los sacramentos, lo que dio argumentos para que el Santo Oficio de la Inquisición también extendiera su jurisdicción sobre el tema de la bigamia, al considerar herejes a los que negaban los sacramentos de la Iglesia católica (en este caso el matrimonio). Ello no es obstáculo para que algunos historiadores hayan encontrado algunos procesos inquisitoriales en fechas anteriores al Concilio de Trento (1563); así J. P. Dedieu (1987: 274-275) cita un proceso inquisitorial por bigamia en 1484, realizado en el tribunal del Santo Oficio de Zaragoza, y Henry C. Lea (1983: 727-729) afirma que hay que esperar a 1524 y 1530 para ver procesos de bigamia en los tribunales de Cuenca y Toledo, respectivamente.

Resumiendo, las competencias en dicho delito se distribuyeron de la siguiente manera: la justicia real tenía la jurisdicción sobre las responsabilidades civiles y penales del reo; la jurisdicción eclesiástica, lo relativo al comportamiento doloso con el párroco o clérigo que llevó a cabo el matrimonio; mientras que a la Inquisición le correspondía determinar si el bígamo creía o no en el sacramento del matrimonio en cuanto doctrina de la Iglesia (Molina 2017: 33; Torres Aguilar 1997: 181). Con todo, es preciso advertir que si la Inquisición justificaba su actuación en orden a ver si existían errores de fe en relación con este delito, lo cierto es que los procesos tramitados por el Santo Oficio no evidencian que las acusadas tuvieran una idea errónea del sacramento del matrimonio, ni distinta de la doctrina de la Iglesia (Candau Chacón 2016: 8-9). Normalmente, los inquisidores que procedieron contra los casados dos veces no los juzgaban en calidad de herejes luteranos ni siquiera pensaban que eran «sospechosos en la fe» o ignorantes de la doctrina de la Iglesia en materia del matrimonio (Manrique 1667: 36; Molina 2017: 35); más bien, trataron el tema de la bigamia desde el punto de vista legal (fraude en el matrimonio) y del escándalo que producía en la sociedad (las mujeres acusadas de bigamia se las colocaba al margen del orden social y muchas de ellas derivaron también en acusaciones de brujas) (Levack 1995: 194-198).

Este enfoque legal produjo que apareciese una abundante literatura en la que, no solo se distinguían varias clases de bigamia, sino que se precisaban los castigos que se debían imponer a cada una de ellas. Los manuales de inquisidores, como el de Cesare Carena (Carena 1669: 91-92), lo especificaban con claridad; pero fue el inquisidor García de Trasmiera, quien más ampliamente desarrolló la legislación inquisitorial sobre la bigamia (García Trasmiera 1638: 4). Si en el libro I de su tratado dividía el delito de bigamia en tres clases, era en el libro II donde trataba la actuación del Santo Oficio contra este delito. De esta manera, si 
durante la Edad Media se había tratado como delito de mixti fori tras el Concilio de Trento, la Inquisición española se hizo cargo del tema enfocando el delito desde el punto de vista de la herejía. Con todo, la Inquisición se arrogó la potestad de juzgar tales delitos por encima de otras instituciones, como afirmaba Juan de Hevia, quien reconocía que, pese a que la bigamia era de fuero mixto, solo los inquisidores intervenían en ellos (Hevia de Bolaños 1657: n. ${ }^{\circ}$ 126; Gacto Fernández 1990: 132).

La bigamia, desde el punto de vista procesal, ha sido la fuente más utilizada por los historiadores para realizar sus investigaciones, lo que les ha permitido realizar estudios muy completos sobre el número de casos, listas y estadísticas; esto es, análisis empíricos, con escaso aprovechamiento de los diversos aspectos (sobre todo antropológicos, sociales y humanos) que aportan los documentos, pues, en el caso de los procesos por bigamia resulta más importante lo que se calla que lo que se expresa.

\section{El proceso de bigamia en el Santo Oficio}

Aunque en el Derecho inquisitorial, la bigamia se presentaba como un delito merecedor de pena arbitraria, pues la sanción estaba en relación con la calidad de la persona y la circunstancia del delito (Gacto Fernández 1990: 157-159), los castigos aplicados a las mujeres bígamas siempre fueron penas de vergüenza pública y azotes junto con el exilio temporal, entre tres y cinco años alejadas de su familia y lugar donde vivían (Poska 2000: 234-240); es decir, penas que llevaban consigo la exclusión social a través del deshonor y del alejamiento físico. En el conjunto de documentos que he consultado se puede descubrir una división latente apriorística en la mente del legislador que distinguía entre «mujeres honestas» y «malas mujeres», basada casi exclusivamente en criterios referentes a su moral sexual. Dentro de la primera categoría, se realizaba, a su vez, otra división: solteras y casadas; la legislación se ocupaba preferentemente de estas últimas (Sarrión Mora 2003: 27-28). La mayor parte de ellas procedían de condición social humilde, por lo que no es raro que aspirasen a integrarse socialmente o escalar peldaños en la estructura social si el marido las abandonaba (Pascua Sánchez 1998). Así se deduce de los argumentos que las acusadas esgrimían para defender su inocencia ante la justicia del Santo Oficio, todas ellas recurrían a su situación de soledad, miseria o maltrato que padecían, lo que les obligaba a buscar una nueva situación estable (a través del matrimonio) que les impidiese caer en marginalidad social.

El proceso de María Rodríguez Zerezo es un buen ejemplo de lo que afirmo. En este caso, el delito de bigamia fue utilizado por un sector dominante de la villa de la Fuensanta (cercana a La Roda, Albacete) para excluir a la protagonista de la 
integración en la elite social a la que aspiraba. La acusación de bígama sirvió para marginarla, humillarla y, en buena medida, para provocarle la muerte a causa de las vergüenzas padecidas.

\section{María Rodríguez Zerezo, acusada de bíGama por el tribunal del Santo Oficio de la Inquisición de Cuenca}

María Rodríguez Zerezo, natural y vecina de la Fuensanta (villa cercana a La Roda), había nacido en torno a 1715 en una familia pobre. Ella misma declaraba ante los inquisidores de Cuenca que no sabía leer ni escribir. A los dieciocho años contrajo matrimonio (en 1733) con Cristóbal Ortelano Muñoz, también vecino de la Fuensanta, de su misma edad y tan pobre como ella. Tras dos años de casados, Cristóbal la abandonó, junto a un niño que habían tenido durante este tiempo, para buscar algún medio de subsistencia; con este objetivo se alistó en el ejército en Andalucía. Después de veintidós años de espera, sin tener noticias de su marido (su hijo ya tenía veintiún años de edad), María contrajo nuevo matrimonio con don Pedro Giménez, vecino y médico de la Fuensanta, el nueve de mayo de 1757. Si bien, por lo que se deduce de las declaraciones del proceso, las relaciones de la pareja habían fraguado desde bastantes años atrás:

En diez y ocho de abril de mil setecientos y cincuenta y siete se despachó por el tribunal eclesiástico la dispensación de doblado, cuarto grado de consanguinidad, que obtuvieron María Rodríguez Zerezo y D. Pedro Giménez, naturales de la Fuensanta. Y en la información que precedió fueron testigos D. Christóbal Perona, D. Blas de Perona y Julián González, y ninguno declara que sea viuda dicha María Rodríguez Cerezo, la que tampoco declara sea viuda, y sí que de no efectuarse el matrimonio, quedará deshonrada y desacreditada por haber precedido cópula y no hallará varón igual con qué poderse casar, cuyas diligencias de dispensa se devolvieron al provisor (ADC, Inq., leg. 611, exp. 7.390).

De cualquier manera, bajo la apariencia de normalidad, tanto las relaciones prematrimoniales como la celebración del matrimonio se llevaron a cabo con la oposición de la familia de Pedro Giménez, que era de las más pudientes de la villa y no consideraba a María Zerezo digna de emparentar con un vástago de la familia, que además era el médico del pueblo. Las disputas y amenazas para destruir el matrimonio debieron ser tan fuertes que ambos cónyuges se dirigieron al provisor de la diócesis y canónigo de Cuenca, el licenciado don Lorenzo Calvo de la Cantera, advirtiéndole

que estando libres y en libertad para contraer matrimonio como lo tienen estipulado, lo han llegado a entender los parientes del dicho don Pedro y llevado tan a 
mal que por estorbarlo y frustrarlo han proferido muchas y graves amenazas que se teme puestas en execución, logren semejante mal intento y de aquí resultar embarazos e inconvenientes graves y todos nacidos de considerarlo proporcionado y habilitado en la facultad de medicina y de menor edad que la susodicha y esta muy pobre, causa que les impele y disuaden a que se reponga el ánimo y no contraiga dicho matrimonio con ella, contra su deshonor y obligación exponsalicia contraída reciprocamente, y coadyuvando a las impediencias [sic] el cura de aquel pueblo por la mucha estrechez y amistad con dichos parientes de mi parte, estando divulgando todos que, cuando no lo estorben por bien extrañas circunstancias llevándolas adelante, han de acaecer muchas discordias para obviarlas y otros embarazos.

Dado que don Pedro Giménez sabía las buenas relaciones que existían entre sus padres y el cura del pueblo, rogaba al provisor del obispado de Cuenca que la información sobre la consanguinidad (en cuarta generación) que tenía con María Zerezo la realizase el párroco de Tarazona, pero no el de la Fuensanta porque no se fiaba de su actuación. De la información de los testigos a quien interrogó el cura de Tarazona se concluía que ambos pretendientes eran libres y solteros, y que no pensaban en profesar en institución religiosa.

Con todo, conocedores de la doctrina de la Iglesia en materia de matrimonio, María se apresuró a demostrar que su primer marido ya era difunto y, por tanto, se encontraba libre para contraer nuevo matrimonio. Para ello, escribió cartas a los diversos regimientos militares de Andalucía en los que le habían dicho que podrían dar razón de su persona, pero nadie aportó dato alguno, excepto el capitán del regimiento de Dragones de Caballería ligera de Edimburgo en Algeciras, quien le contestó que, en efecto, Cristóbal Muñoz había sido soldado bajo sus órdenes, pero que había desertado en 1737, «en el Puerto de Santa María» y desde entonces «no se ha tenido más noticias de él».

Las pesquisas realizadas y los documentos y cartas recogidos parece que fueron suficientes y fiables para que el párroco de La Roda permitiera a su teniente cura de la Fuensanta, don Alonso Cano, celebrar el matrimonio, después de que este hubiera sido informado de que Cristóbal Ortelano Muñoz había fallecido en Nechite.

En la parroquia de la villa de Fuensanta, a nueve días del marzo de mil 757 años, habiendo precedido una de las tres moniciones que el Santo Concilio de Trento manda por haber dispensado las otras dos el señor licenciado D. Lorenzo Calvo, provisor y vicario general de la ciudad de Cuenca y su obispado, [...] yo don Alonso Cano Pérez, cura theniente de dicha parroquial, habiendo examinado a los referidos en doctrina cristiana y administrándoles los dichos sacramentos de la penitencia y eucaristía, los desposé in facie eclesiástica, siendo los testigos Miguel Corredor, Cristóbal López y Julián González Mateo, vecinos de dicha villa. Y lo firmo Alonso Cano Pérez (ADC, Inq., leg. 611, exp. 7.390). 
Bien es cierto que varios años después, cuando en pleno proceso inquisitorial fuese interrogado el párroco de La Roda, don Miguel Tamayo Albornoz, que para estas fechas ya se había trasladado a residir como presbítero del Oratorio de San Felipe Neri en Cuenca, declaró que María Zerezo no actuó con honestidad en la preparación de documentos para celebrar su matrimonio, pues no dejaba clara su viudedad. En torno a este punto se centraron los interrogatorios y acusaciones de los inquisidores. El párroco de La Roda descargaba su responsabilidad de haber dado consentimiento para celebrar el matrimonio a su teniente de la villa de Fuensanta (Alonso Cano), alegando que este asintió

\begin{abstract}
al matrimonio en virtud de los dichos despachos por constarle que a María, habiendo acudido primero ante al Provisor con presentación de una carta de uno que se decía cura de Nechite, en el arzobispado de Sevilla, el que se refería la muerte de dicho Christóbal, había mandado el Provisor librar requería para que se comprobase sin antes haber evacuado las diligencias prevenidas en dicha requisitoria, y callando este pasaje había acudido posteriormente solicitando se librase comisión al cura de Tarazona para la justificación de sus libertades en cuya virtud fue librado el despacho primero de la dispensa de las dos amonestaciones, y que el declarante en vista de dichos despachos, dijo al expedido su theniente que no tenía reparo ninguno que los podía casar cuando quisiere por lo que se le amonesta declare qué motivos tuvo para haber dicho a su theniente no tuviesen reparo en asistir a dicho matrimonio (ADC, Inq., leg. 611, exp. 7.390).
\end{abstract}

\title{
3.1. Interrogatorio de la InQuisición a María Zerezo
}

El matrimonio formado por don Pedro Giménez y María (Rodríguez) Zerezo se mantuvo unido durante los primeros seis años. No obstante, durante este tiempo se vio sometido a continuo acoso por los rumores y asechanzas rendidas por la familia del médico, que no se resignaba a admitir esta unión. Los padres y los hermanos de Pedro Giménez supieron rentabilizar la amistad que mantenían con el clero de la comarca y llegar a establecer relación con el provisor del obispado de Cuenca, don Lorenzo Calvo de la Cantera, para abrir pesquisas sobre un asunto aparentemente ya zanjado, como era la revisión de los documentos aportados por María para la celebración de su segundo matrimonio, en los que se descubrió que no había certificado de defunción de su primer marido, sino que se había asumido la certeza de su muerte por datos contenidos en cartas y por declaraciones o noticias personales. Con estos argumentos, el provisor del obispado consiguió implicar, a su vez, al único inquisidor (que entonces tenía el tribunal de Cuenca), el licenciado don Diego de Viana, para que el asunto recayera bajo jurisdicción inquisitorial. Todo ello dio por resultado que, el 23 de abril 1763, María Zerezo se encontrase realizando su primera declaración en la sala del secreto de dicho tribunal: 
En la Inquisición de Cuenca a veinte y tres días del mes de abril de mil setecientos sesenta y tres años, estando en la audiencia de la mañana el señor inquisidor lcdo D. Diego de Viana, que asiste solo, mandó entrar en ella a una mujer, que entregó una carta, de quien fue recibido juramento de decir verdad y guardar secreto, así en esta audiencia como en las demás que se tuvieren con ella y de lo que viere y entendiere y pasare sobre dependencia.

Preguntada cómo se llama, de dónde es natural, qué edad y estado tiene.

Dijo se llama María Rodríguez Zerero, natural de la villa de la Fuensanta, de estado casada con D. Pedro Ximénez, médico de dicha villa y de edad de cuarenta y nueve a cincuenta años, poco más o menos.

Preguntada si es cristiana bautizada y sabe o presume la causa por qué se le ha mandado comparecer en este Santo Oficio.

Dijo que es cristiana bautizada y que no sabe ni presume la causa por qué ha sido llamada y que no obstante haber estado indispuesta por manifestar obediencia al santo tribunal, ha venido aunque con algún trabajo.

Preguntada cuánto tiempo ha que contrajo matrimonio con D. Pedro Ximénez y qué estado tenía cuando lo contraxo.

Dixo que hará seis años a nueve de mayo que contrajo matrimonio con dicho D. Pedro y que al tiempo de contraherle se hallaba viuda hacía veinte y dos años.

Preguntada de quién se hallaba viuda y cómo se llamaba su primer marido y dónde murió.

Dijo que su primer marido se llamaba Christóbal Muñoz Ortelano, natural que fue de la misma villa de Fuensanta, y que habiendo sentado plaza de soldado dicho Cristóbal en el regimiento de Villaviciosa, después de dos años y algo más de casados, dejándola con un hijo de nueve meses, pasados algunos años sin sabido de su paradero, le avisaron de La Roda que había en el correo una carta con sobre escrito para la declarante y en su defecto para el teniente de cura de la Fuensanta y habiendo pasado la declarante para La Roda, sacó del correo la carta y restituida a la Fuensanta se la entregó al teniente de cura cerrada y habiéndola abierto y leído delante de la declarante y de otras personas de la casa de dicho teniente, llamado D. Alonso Cano, entendió la declarante constaba por ella, que había muerto dicho Cristóbal en un lugar que no se acuerda del nombre de él y sí solo que era del Arzobispado de Sevilla, y que había dejado encargado se le dijese una misa en el altar de Nra. Sra. de los Remedios, que está en la iglesia en el convento de la SSma Trinidad de dicha Villa y que el dicho teniente después de leída, se la entregó a la declarante y dio a ver a D. Blas de Perona y a Pedro Muñoz Ortelano, hermano del referido Christóbal y a Pedro Ximénez, vecinos de dicha villa, primo hermano del referido Cristóbal y a otras personas que ya fallecieron y que en virtud de constar por dicha carta de la muerte de su primer marido trató de contraer el segundo con dicho don Pedro.

Preguntada por el paradero de dicha carta y qué diligencias practicó para asegurarse si era cierta la muerte de dicho Cristóbal y conseguir la licencia para contraer segundo matrimonio y de quién era la carta que informa de la muerte de dicho Christóbal. 
Dijo que la carta se acuerda era escrita por un teniente del lugar donde había muerto dicho Christóbal y que refería haber escrito otras, noticiando lo mismo, y que por no haber tenido respuesta, había puesto en el sobre escrito también al theniente cura de dicha villa. Y que la referida carta la traxo la declarante a esta ciudad y se la entregó al provisor para que la viese y le concediese licencia para contraer segundo matrimonio y se quedó con ella. Y habiendo hecho más reflexión, dijo que el provisor solo le respondió que estuviese con un procurador devolviéndole la carta con la que se fue al servicio al oficio de D. Phelipe Romero, notario de la audiencia episcopal y estando este y su hermano D. Ignacio y un escribiente, la leyeron y se quedaron con ella, diciéndola que por el correo le avisarían y con efecto le avisaron, enviándole una carta a la declarante al theniente de el lugar, donde había muerto el citado Christóbal y no tuvo respuesta y lo atribuyó a que por haber escrito la antecedente en que relacionaba haber scrito otras y haberse perdido acaso habría sucedido lo mismo que con las otras. Se escribió a Cuenca por un notario de Minaya, llamado Martín de Minaya, y le enviaron un despacho para que hiciera información de libertad y con efecto se hizo la información por ante el cura de Tarazona, y habiéndola hecho en el mismo lugar de Tarazona, de donde fueron los testigos y la declarante y habiendo enviado dicha información a Cuenca, le concedieron licencia para que leyéndose una amonestación y no resultando impedimento, el theniente asistiese al matrimonio que pretendía contraer con dicho D. Pedro, y que desde que dejó la carta en el oficio de Don Phelipe Romero, no la ha vuelto a ver ni sabe su paradero, y que el mismo don Phelipe Romero trajo de Roma dos dispensas de los grados de parentesco que intervenían entre la declarante y dicho D. Pedro por no haberse especificado todos los grados en la primera dispensa de las que tuvieron noticia los vecinos de dicha villa y el theniente de cura, quien en vista de la licencia que había sacado de Cuenca para poder contraer matrimonio, le dijo que ya podía casarse y en efecto asistió al segundo matrimonio que contrajo con el citado D. Pedro. Y en este estado se mandó casar en dicha Audiencia. Y habiéndole leído lo que tiene declarado, dijo estaba fielmente escrito y que no tiene qué añadir ni enmendar, que en ello se afirmaba y ratificaba y no firmó por no saber (ADC, Inq., leg. 611, exp. 7.390).

La declaración de María Zerezo parecía haber aclarado todas las dudas que existían sobre el problema; sin embargo, el inquisidor tenía en mente que la volvería a llamar, por lo que le mandó que «no saliese de esta ciudad sin orden del tribunal, [bajo] pena de doscientos ducados y que concurra al tribunal todos los días que le hubiese». Solamente habían transcurridos tres días cuando de nuevo fue requerida en la sala del secreto para preguntarle si había recordado alguna cosa más de su asunto.

Dijo que solo ha acordado que la carta que vino del lugar de Sevilla, en que se refería la muerte de Christóbal Muñoz Ortelano, la leyó también después que el theniente, Juan Gómez Carretero, vecino de dicha villa y notario. 
Preguntada qué tiempo pasó desde que puso en el correo de La Roda la carta que le enviaron de Cuenca para que se comprobase si era cierta la muerte hasta que solicitó le enviasen de Cuenca la comisión o despacho para la justificación de su libertad, que tiene dicho se ejecutó por el cura de Tarazona, y si el administrador del correo de La Roda era el mismo que le entregó la primera carta en que constaba la muerte y cómo se llamaba dicho correo.

Dijo que desde que puso la carta que le enviaron de Cuenca en el correo de La Roda para el theniente o cura del lugar en que había muerto dicho Christóbal hasta el tiempo en que le enviaron el despacho o comisión para la justificación de libertad, le parece pasarían dos años sobre poco más o menos y que el correo de La Roda era el mismo que en las dos ocasiones entregó una carta y recibió la otra y no sabe su nombre ni apellido y si que comúnmente le llamaban el Maestro el que ya algunos años que murió.

Fuela dicho que no es regular que en el tribunal de Cuenca le diesen carta que pudiese enviar al cura o theniente del arzobispado de Sevilla que había escrito la muerte, sino carta requisitoria abierta para que se presentase ante el provisor de Sevilla y este mandase al cura o teniente del lugar donde se decía había muerto, compulsarse la partida de entierro si la hubiese y legalizada, la enviase al tribunal de Cuenca, y así que declare la verdad de lo que ocurrió sobre este particular.

Dijo que en lo que en realidad pasó fue que habiéndole manifestado la referida carta que le enviaron de Cuenca a Juan de Oñate, notario de La Roda (que ya es difunto) para que le dijese lo que había de executar, habiéndola leído poco después que la sacó del correo de La Roda, la declarante la expresó que era necesario enviarla para que se evacuasen las diligencias que se prevenían y el dicho Oñate la cerró y puso sobre escrito y se la dio para que la pusiesen en correo y con efecto la puso en él y se volvió a su lugar, llevándose solamente la carta que del oficio de Romero le enviaron, avisándole las diligencias que con la que le incluyeron se habían de hacer en Sevilla.

Preguntada si antes de hacer la información de libertad en [borrón] tuvo alguna noticia de no ser cierta la muerte del dicho Christóbal o si antes de efectuar el segundo matrimonio le dijeron alguna persona o personas que habían visto a su primer marido en algún parage o por algún medio fuera de la expresada carta se aseguró de ser cierta la muerte del citado Christóbal.

Dijo que mucho antes de que se hiciese la información en Tarazona se extendió en el lugar de Fuensanta que dos hombres de La Roda, habían dicho que en Cádiz habían hablado con dicho Christóbal y que después de algún tiempo supo de una vecina, llamada Quiteria Sabuquilla, que los referidos dos hombres se hallaban en su casa con lo que pasó la declarante a la casa de la referida y preguntándole si era la mujer de Christóbal Ortelano respondió que sí. Y les preguntó si les traía carta, a lo que respondieron: ríase v. m. de eso, y habiéndoles dicho que se alegrara de verlo en la laza, dijeron dichos hombres que primero se arrugarían las estrellas que consiguiese el verlo porque estaba muy enfermo y muy desdichado y diciéndoles que si se había muerto se lo declarasen, respondieron que se había muerto pero que estaba muy enfermo y muy desdichado, por lo que hizo concepto que la engañaban 
si poder apurar el fin particular que les movía y añade que esta voz y conservación con los dos hombres de La Roda, cuyos nombres y apellidos ignora fue también antes de llegar la carta en que se refería la muerte, lo que sabe llegó a noticia de D. Miguel Tamayo, cura que era por entonces de La Roda y Fuensanta y actualmente padre de san Felipe de Neri. Y que ninguna otra persona le ha dicho que viviese dicho Christóbal y antes comprobó la incertidumbre de lo que habían esparcido los dos vecinos de La Roda un hermano de dicho Christóbal, llamado Juan Ortelano Muñoz, $[\ldots]$ para averiguar si era vivo su hermano y que después que había desertado del Regimiento, ninguno le había visto ni dado noticia de él, por lo que le tenían por muerto y no ha tenido noticia en contrario la declarante. En este estado se mandó cesar en esta audiencia habiendo añadido que dicho Juan Ortelano murió ya hace años (ADC, Inq., leg. 611, exp. 7.390).

María Zerezo fue citada nuevamente al día siguiente y aunque dijo que no tenía ninguna cosa que decir, el inquisidor le preguntó la edad de Cristóbal Ortelano cuando contrajo matrimonio con ella. «Dijo que solo le llevaba tres meses a la dicha declarante cuando se casaron que fue teniendo ambos poco más de diez y ocho años», a lo que el inquisidor argumentó que teniendo la misma edad, era muy probable que su marido aún estuviere vivo ya que no era viejo, con lo que podría haber incurrido con mala fe contra el sacramento del matrimonio y «sintiendo mal de lo que nuestra Santa madre Iglesia nos enseña», a lo que la acusada respondió que

no siente mal de lo que enseña Nra Santa madre Iglesia y que se casó baxo de la buena fe de lo que le había dicho el hermano de su marido, que ya tiene referido, y cartas que tuvo la declarante de que no le habían visto los de su Regimiento desde que desertó en el Puerto de Santa María y de lo que tiene referido de la carta del arzobispo de Sevilla en que se refiere la muerte. Y que no tiene más que decir (ADC, Inq., leg. 611, exp. 7.390).

Al día siguiente, el inquisidor nuevamente la citó para preguntarle si algún «vecino de un lugar inmediato que con los dos de La Roda a Cádiz, le dejó recado de haber visto en Cádiz a dicho Christóbal y que había encargado le dijese, le enviase diez pesos para sacar la licencia de su capitán y restituirse a hacer vida maritable con la declarante». María contestó que

ningún vecino de la Fuensanta ni de otro lugar inmediato le ha dado tal recado de que cambiase diez pesos a su marido Christóbal ni dicho que este viviese a excepción de lo que le dijeron los dos vecinos de La Roda en la forma que tiene declarado, y que Miguel Corredor, marido que fue de Quiteria Sabuquilla, ya difunta, la que estuvo presente a lo que dijeron los dos vecinos de La Roda, fue testigo cuando contrajo matrimonio con dicho D. Pedro, y que si este había entendido de su mujer o de otra persona que vivía el referido Christóbal, lo hubiera declarado. 
Ante la firmeza y seguridad con la que contestaba María sin incurrir en contradicción con lo expresado en la primera declaración, el inquisidor (que no estaba convencido de la sinceridad y buena intención con la que actuaba María) ordenó encerrarla en la cárcel, en casa del alcaide, donde estaba como residente, «sin salir más que a misa los días festivos». Asimismo ordenaba - siguiendo el procedimiento ordinario - enviar la causa al Consejo de la Inquisición para que fuera revisada antes de proceder a la declaración de los testigos y a la acusación formal.

\subsection{Las acusaciones de Los testigos}

En la audiencia del 13 de julio, tras recomendarle una vez más que dijese si recordaba alguna cosa no declarada, el fiscal decidió publicar la declaración de los testigos que habían depuesto contra ella, ante lo que María Rodríguez Zerezo no se inmutó. Las acusaciones de los testigos de cargo no aportaron a la causa más datos de los ya conocidos. Las acusaciones estaban hechas por personajes evanescentes, difíciles de identificar, que se hacían eco de noticias oídas, con poca lógica y fundamento y que, desde luego, no habían vivido.

El primer testigo afirmó que

un día del mes de enero de mil setecientos sesenta y dos, dice sabe vio y oyó que habrá como cinco años, poco más o menos, que saliendo un día a labrar, se encontró con un hombre de cierta villa, que venía de Cádiz, y preguntando al testigo si era de Fuensanta y si conocía a esta reo, mujer de Christóbal Muñoz Ortelano, y respondiéndole que era de dicha villa y que conocía a esta reo, le dijo dicho hombre, dígale v. m. que su marido Christóbal Muñoz le envía a decir que le remita diez pesos para con ellos lograr licencia para venirse a su casa, que está siendo soldado en Cádiz, a lo que el testigo le replicó, cómo puede ser eso de vivir Christóbal Muñoz, si esta reo se casa y se amonesta el domingo con cierta persona que expresó, y dicho hombre le dijo: «ahora me ha puesto v. m. en mayor cuidado y si no ha de hacer la diligencia, me vuelvo desde aquí», a que el testigo le dijo fuese con Dios, que lo haría (ADC, Inq., leg. 611, exp. 7.390).

Es preciso recordar que Cristóbal Muñoz había desertado del ejército en 1737, como testificaba el sargento mayor de su regimiento, por lo que aun cuando el tal peregrino intentase dar mayor verosimilitud a su relato, añadiendo ciertos rasgos de su fisonomías («era de mediana estatura y estaba algo cargado y de color un poco moreno y que si hoy vivía, tendría cincuenta y dos años poco más o menos»), no resultaba creíble.

Mucho más extraña fue la afirmación de otro testigo, a saber, «que habrá diez años oyó decir a un soldado de su Regimiento que ha venido de Buenos Aires, que en dicha población de Buenos Aires se quedaba Christóbal Muñoz bueno y sano y que discurría se vendría en otra ocasión a España»; este testigo no fue 
identificable, dado que había pasado por la Fuensanta sin saber ni especificar por qué causa y después de difundir esta noticia, había desaparecido.

Sin duda ninguna, la acusación más grave fue la realizada por un testigo que dijo haber visto a

esta reo [María Zerezo] que iba diciendo por la calle: ahora se verá si putas, borrachos y cabrones dicen que no me tengo de casar; y prosiguiendo encontró este declarante al theniente cura en su puerta, el que le dijo ven y verás una carta que esta reo le había entregado cerrada, la que leyó el declarante y parecía ser del cura de la villa de Nechite, arzobispado de Sevilla, de cuyo nombre no hace memoria y sí que venía autorizada de dos notarios apostólicos, y que el uno tenía dos firmas puestas y se llamaba Sebastián García y advirtió que el cura no había puesto la partida de difunto de dicho Cristóbal y solo decía cómo saliendo después de comer por la orilla de dicha villa le llamaron porque estaba allí un hombre muriéndose y habiendo llegado, le habían entregado el enfermo, que era Christóbal Muñoz, casado con María Rodríguez Zerezo, de la que tenía un hijo llamado Christóbal, que si acaso moría, se escribiese a su mujer, la que no le había dado motivo para que la dejara, para si quería casarse o no. Y que después que le había hecho este encargo, había ido deprisa a la Iglesia para administrarle los santos Sacramentos y cuando volvió ya lo halló difunto. Y también dice esta carta que no había sido pedido por esta reo este relato y solo lo hacía por caridad y el encargo que el difunto le había dejado de que escribiera a su mujer (ADC, Inq., leg. 611, exp. 7.390).

Ciertamente, la carta resultaba sospechosa de que hubiera sido escrita por orden de María Zerezo como el propio testigo se encargó de aclarar, pues añadía que el teniente cura le dijo:

no ve v. m. cómo esta carta es en un todo falsa, pues dice aquí el cura de Nechite no había sido pedida por dicha María, y esta, antes que v. m. la avisase, iba diciendo por la calle ahora verán si putas, borrachas y cabrones dicen que no me puedo casar, luego lo sabía y solicitó y dicho cura dice otra cosa. Y además, no ve v. m. que estas dos firmas del notario Sebastián García es la una muy distinta de la otra, luego falsa es en un todo la carta (ADC, Inq., leg. 611, exp. 7.390).

Para confirmar que la noticia era falsa, el propio testigo argumentaba que la villa de Nechite no se encuentra en el arzobispado de Sevilla, sino que pertenece al de Granada, al mismo tiempo que, para descargar de responsabilidades del teniente cura, que había celebrado el matrimonio,

le recomendó tomando la carta del cura de Nechite y vayan a Cuenca y el provisor en vista de ella determinará lo que gustare. Y habiendo entregado dicha carta a esta reo, sabe fue a Cuenca y que el provisor libró requisitorio para que la parte fuera a 
la villa de Nechite y trajese certificada la partida de difunto de Christóbal Muñoz para enseguida dar providencia (ADC, Inq., leg. 611, exp. 7.390).

Las declaraciones del resto de los testigos resultan más chuscas. Uno de ellos afirmaba que el mismo año de que María Zerezo celebrase el matrimonio con Pedro Giménez (1757), «se dijo» que habían visto a su primer marido en la villa de Sisante por el tiempo de la vendimia («aunque no hace memoria a quien lo oyó») y que por entonces le hurtaron una burra a don Pedro (sin especificar por qué se encontraba en Sisante) y «se dijo» que había sido el tal Cristóbal quien la había robado en venganza de haberse casado con su mujer. Para dar mayor verosimilitud al suceso, el testigo aportaba algunos rasgos físicos del citado Cristóbal: «de dos varas de alto, algo enjuto y carilargo y le parece tenía una cicatriz en la mejilla derecha». Para averiguar la verdad de esta acusación, los inquisidores de Cuenca ordenaron al comisario de Sisante que verificase el suceso, quien contestaba diciendo que los vecinos a quienes preguntó por el tema «se reían con lo que conocieron los presentes que aquello no tenía fundamento [...] lo que es una manifiesta falsedad porque consta ciertamente quién es el que la ha hurtado» y no precisamente al médico de la Fuensanta (ADC, Inq., leg. 611, exp. 7.390, f. 157r).

Finalmente, otro testigo comentaba que, por los años de cincuenta y cuatro,

hallándose noticioso de la nota que daban esta reo y D. Pedro Ximénez con su comunicación, reconvino por dos o tres veces a este D. Pedro para que evitase las entradas [a la casa de María] y no bastando, lo notificó al cura de que resultó mandarle salir del pueblo, y habiendo estado ausente como dos años, volvió a su comunicación y hizo público venía a casarse con esta reo, y manifestándole el declarante no podía tener efecto si no hacía constar en suficiente forma el fallecimiento de Christóbal Muñoz, con quien estaba casada. Y que a pocos días se introdujo en su casa esta rea y le dio una carta cerrada expresándole de palabra «ahora veremos si se detiene v. m. en que me case», con lo que se salió y, abierta dicha carta, venía un testimonio de dos notarios, al parecer de la villa de Nechite, relacionado haber muerto en una calle de dicha población el referido Christóbal Muñoz, y el cura de dicha villa en la justicia contestaba con dichos notarios adelantando que dicho difunto le había dejado encargado le participase a su mujer la muerte por su acaso quería casarse.

Tras los testigos y la contestación de María, los inquisidores le pidieron su genealogía que demostraba ser una familia humilde y limpia, integrada en la villa de la Fuensanta, que nunca habían tenido problemas con la Inquisición. Su hábitat y vida se reducía a su villa; nunca, declaraba, «había salido de la Fuensanta, si no es a algún lugar de aquella comarca». A continuación se le hicieron preguntas en relación con el grado de conocimiento que tenía de la religión católica y doctrina de la Iglesia: 
Preguntada si es cristiana bautizada y confirmada y oye misa y confiesa y comulga en los tiempos que manda la Santa Madre Iglesia. Dijo que está bautizada en la Iglesia de Fuensanta y que en la misma fue confirmada por un obispo que no se acuerda de su nombre y que ha confesado y comulgado en los tiempos que manda la Santa Madre Iglesia y en otras festividades y que la última vez se confesó con el teniente cura el día antes que saliese para venir a esta ciudad y comulgó dicho día. Oye misa todos los días de fiesta y los más que no lo son. Signóse y santiguóse y dijo el padre nuestro, salve, ave María, credo en romance y respondió medianamente a las preguntas que se le hicieron [sobre religión]. Preguntada si sabe leer y escribir, dijo que no.

\subsection{ACUSACIÓN DEL FISCAL}

Con todos estos datos y habiendo comprobado el alto grado de instrucción religiosa que tenía la encausada, el fiscal del tribunal de Cuenca dictaba la sentencia haciendo referencia en la introducción a cierta similitud con las ideas de Lutero y otros herejes (lo que era incierto), acerca de los santos sacramentos:

1. ${ }^{o}$ Primeramente le acuso de que habiendo contraído legítimo matrimonio con dicho Cristóbal Muñoz Ortelano, natural de la misma villa, el día 16 de febrero 1733, en la iglesia parroquia de la villa, en presencia de D. Rodrigo Fernández Garrido, teniente de cura y de D. Álvaro Muñoz, Juan Rodríguez y Alonso Garrido, como testigos de dicho matrimonio, y no debiendo olvidar la unión inseparable que causa este sacramento, no las penas con que se halla prohibido y condenado por la Santa Iglesia el repudio y la poligamia, esta acusada, sin cierto nuncio de la muerte de dicho marido, antes bien, constándole que vivía y atropellando temerariamente las leyes sagradas, contrajo de facto segundo matrimonio con D. Pedro Ximénez, vecino de dicha villa, y en la misma iglesia parroquial el día 9 de mayo 1757, estando presente como teniente cura D. Alonso Cano y como testigos Miguel Corredor, Christóbal López y Julián González, todos vecinos de la villa de la Fuensanta.

2. ${ }^{\circ}$ Y tem, la acuso de que para contraer este segundo matrimonio se valió de la ocasión de haberse ausentado su primer marido, dejando sucesión legítima y sentando plaza de soldado en el Regimiento de Dragones de Itálica sin que hubiese bastado a contener su temerario arrojo la noticia que le dieron personas que se expresan de que su marido vivía en Cádiz con deseos de dejar el real servicio y de volverse a su casa para cuyo fin le pidió que remitiese cierta cantidad a Cádiz y que tuviese paciencia algunos días.

3. ${ }^{\text {I }}$ Item, que habiendo vivido mucho tiempo amancebada con el dicho D. Pedro Ximénez, causando grave escándalo, dio motivo a que la justicia ordinaria de dicha villa desterrase al expresado D. Pedro, y empeñado en continuar la mala vida, solicitó, habiendo vuelto a la dicha villa el citado Ximénez, que el teniente cura los casase, esparciendo la voz de que había muerto el primer marido y haciéndole repetidas instancias para que asistiese a este segundo matrimonio, quejándose agriamente de las personas que recelaba le embarazaban este diabólico atentado. 
4. ${ }^{\text {o }}$ Ítem, de que viendo que el dicho teniente cura no quiso publicarla ni casarla hasta que hiciese constar en debida forma, la muerte de su primer marido, fingió una carta que sonaba escrita por el cura de Nechite y autorizada de dos notarios en la cual se refería la muerte de dicho Cristóbal Muñoz, pero con tales circunstancias que abiertamente manifestaba su falsa dicha carta y se comprueba con evidencia de que llevándola cerrada en sus manos para entregarla a dicho teniente cura iba publicando por la calle su contenido y diciendo en altas voces, ahora se verá si putas y cabrones me impiden el que me case con D. Pedro Ximénez.

5. ${ }^{\circ}$ Ítem, que no habiendo dado asenso a dicha carta el expresado teniente cura por considerarla falsa, como en la realidad lo es, mediante averse averiguado que no hay lugar de Nechite en el arzobispado de Sevilla, en donde sonaba escrita, tuvo valor dicha acusada para presentarla al provisor de esta ciudad pidiendo que en vista de ella se le diese libertad para contraer matrimonio con dicho Ximénez; pero lejos de asentir a esta pretensión, el provisor libró despacho requisitorio para el de Sevilla a fin de comprobar el contexto de dicha carta, y aunque esta acusada tiene confesado que a ella misma se le entregó dicho requisitorio y que lo puso en el correo de La Roda, se convence de haber jurado falso en este particular, porque consta que el dicho requisitorio se remitió de esta ciudad a cierto vecino de la Fuensanta, y que este lo entregó al dicho D. Pedro Ximénez, aconsejándole que lo llevase a Sevilla y practicase por sí mismo esta diligencia si quería casarse con dicha acusada.

6. ${ }^{\circ}$ Que sin haber usado de dicho requisitorio, antes bien, ocultando maliciosamente como se presume, atento a que no parece ni se halla en los oficios donde corresponde y dejando pasar largo tiempo, sin duda para que se olvidase el provisor de todo lo referido, acudió segunda vez ante dicho provisor, callando el pasaje antecedente, fingiéndose libre y soltera y pidiendo juntamente con dicho Ximénez que se recibiese información de su libertad, recusando para ello al cura de Fuensanta y de que consiguiente ser le dispensase las tres amonestaciones y se librase despacho para que dicho cura los casase como de facto lo consiguieron.

7. ${ }^{\circ}$ Que habiendo logrado el referido despacho, por los medios expresados, contrajo el dicho segundo matrimonio entre tres y cuatro de la mañana del día 9 de mayo 1757, recelosa y acusada de la propia mala conciencia y temiendo que haciéndolo en otra hora regular hallaría algún embarazo su temerario arrojo.

8. ${ }^{\circ}$ Finalmente la acuso de que añadiendo delitos a delitos ha faltado a la religión del juramento en las tres audiencias que se le han dado, procediendo en ello con suma protervia y consumada malicia, pues no ignorando que debió decir y confesar la verdad, se ha mantenido negativa, haciéndose indigna de la piedad que observa este tribunal con los humildes y verdaderos confidentes sin que le pueda excusar ni disculpar el olvido en hechos tan graves y pendientes. Por tanto, a V. S. pido y suplico que habida mi relación y acusación por verdadera, se sirva declararla por bien probada en la parte que vaste y a esta rea por autora de los delitos expresados condenándola a las penas establecidas por derecho y estilo del Santo Oficio, mandándolas imponer en su persona para que le sirvan de castigo y a otras de escarmientos según justicia que pido y juro. 
Otro sí, en caso necesario y sin perjuicio ni disminución de mis probanzas, a V.S. pido y suplico que dicha acusada sea puesta a cuestión de tormento, repitiéndole las veces y con la duración que permite el derecho hasta que diga y confiese enteramente la verdad por ser justicia que pido. Secreto de la Inquisición de Cuenca y mayo, 15 de 1763. Dr. D. Augusto Gómez de Anguiano (ADC, Inq., leg. 611, exp. 7.390).

María Rodríguez Zerezo no reconoció las acusaciones, pero tampoco se le dio tormento, sino que contestó a cada uno de los cargos con una seguridad propia de las personas que son conscientes de su verdad, comenzando por reconocer que sabía lo que manda la Iglesia en relación con el matrimonio: «dijo que siente bien de los santos sacramentos y que sabe que la que está casada no puede pasar a contraer segundo matrimonio sin haber muerto su primer marido, y que si se casó segunda vez fue después de veinte y dos años de ausencia de su primer marido por haber tenido carta de que era muerto».

\section{Al capitulo primero respondió:}

Dijo que es cierto que contrajo los matrimonio en los días que se expresan, pero el contraer el segundo matrimonio fue por haber tenido noticia de la muerte de su primer marido por la carta expresada a la cabeza de la acusación y por haberle dicho Juan Ortelano, hermano de dicho Cristóbal, que bien se podría casar esta confesante porque su hermano era muerto, lo que podrá deponer Pedro Muñoz Ortelano, hermano de los dichos y otros parientes.

Al capitulo segundo:

Dijo que ninguna persona le ha dicho que enviase dinero a Cádiz a dicho Cristóbal para saliese del servicio real y que solo es cierto lo que tiene declarado de que dos hombres que dijeron eran de La Roda, habrá doce o trece años, le expresaron que lo habían visto, con lo demás que tiene declarado en una de sus audiencias. Pasó con dichos hombres en casa de Quiteria Sabuquilla.

\section{Al cuarto capitulo:}

Dijo que es falso haya fingido carta alguna, dado consentimiento para que la fingiesen, suponer la muerte de su primer marido y solo verdad; que un hortelano de la Fuensanta, llamado Antonio, que ya es difunto, la dijo fuese a La Roda a por una carta que había en el correo y un sobre para la declarante y en su defecto para el theniente, y habiendo pasado al correo de La Roda esta confesante la sacó y sin abrirla se la llevó al cura D. Alonso Cano.

Artículo quinto:

Dijo que abriéndola leído el teniente cura de la Fuensanta, le dijo que habiendo muerto su marido ya se podía casar con otro, pero que para mayor seguridad, convenía la presentase ante el provisor, para lo que después de habérsela presentado al cura de La Roda, según le dijo el mismo teniente, se la volvió a la confesante, y habiéndola presentado ante el provisor de este obispado, para que le diese licencia de contraer con dicho D. Pedro para que le diese licencia de contraer y díjole estuviese con un procurador, se fue como tiene declarado en sus audiencias al oficio del Notario de 
Romero y la dejó allí por haberlo dicho que por el correo la avisarían la resolución y con efecto a los pocos días de haber vuelto a su lugar, recibió por el correo de $\mathrm{La}$ Roda una carta con sobreescrito a esta confesante y executó lo que tiene declarado sobre este particular y solo añade que ignora si le devolvieron la carta que dejó en el dicho oficio de Romero, y que es incierto lo que se refiere de haber ido dirigida la carta a un vecino de la Fuensanta y entregándola este a dicho D. Pedro Ximénez. Al capitulo sexto:

Dijo que no ha callado nada por malicia, ni tiene más que decir, que lo que tiene declarado en las audiencias sobre el contenido de este capítulo.

Al capítulo séptimo:

Dijo que es falso que contrajo el segundo matrimonio entre tres y cuatro de la mañana, pues fue entre ocho y nueve de la mañana, estando la iglesia llena de gente y sacerdotes de La Roda, diciendo misa.

\subsection{SEnTENCIA Y ABJURACIÓN}

El 19 de octubre de 1763, los inquisidores dictaban sentencia en la sala del tribunal a puerta abierta sin demostrar que el primer marido de María Zerezo (Cristóbal Hortelano) estaba vivo o muerto:

estando forma de penitente, abjure de levi, sea gravemente reprendida, adbendita, y conminada, desterrada cinco años de la villa de la Fuensanta, de la de Madrid, corte de su Majestad y ocho leguas su contorno y a que sirva en el hospital de esta ciudad a las pobres enfermas que en él hubiere en los expresados cinco años, haciendo en los primeros quince días ejercicios espirituales con dirección de la persona que el tribunal le señalare, con la que se confesará generalmente; condenándola a que no pueda tratar, comunicar no cohabitar con D. Pedro Ximénez, ni este con ella, y a ambos a que no puedan disponer de sus personas en el interim, que no hagan constar haber muerto Christóbal Muñoz Ortelano, su legítimo marido, antes de la contracción de facto de el segundo matrimonio y obtengan licencia del ordinario para poder cohabitar. Que los testigos que depusieron ser libre y soltera la referida María Rodríguez Zerezo, sean seriamente reprendidos y comminados con la implicación de las penas establecidas, si en adelante incidieren en dicho delito y se saque de proceso por concuerda lo que de él resulta contra dicho D. Pedro Para lo que haya lugar.

Y luego acabado el dicho Auto, la mencionada María Rodríguez Cerezo abjuró públicamente los errores en la forma siguiente:

Yo, María Rodríguez Cerezo, natural de la villa de la Fuensanta, de este obispado, que aquí estoy presente ante vuestras señorías, como inquisidores que son contra la herética pravedad y apostasía en esta ciudad de Cuenca y su partido por autoridad apostólica y ordinaria, puesta ante mí esta santa cruz y los santos Evangelios, 
que con mis manos corporalmente toco, reconociendo la verdadera y católica fe, abjuro, detesto y anatematizo toda especie de herejía que se levante contra la Santa Fe Católica y Ley evangélica de nuestro Redentor Jesucristo y contra la santa sede apostólica e iglesia Romana, especialmente aquella de que yo ante V. Señorías he sido acusada y estoy levemente sospechosa y juro y prometo de tener y guardar siempre aquella fe que tiene, guarda y enseña la Santa Madre Iglesia y que siempre seré obediente a Nuestro Señor el Papa y a sus sucesores que canónicamente sucedieren en la silla apostólica y a sus determinaciones y confieso que todos aquellos que contra esta Santa fe vinieren, son dignos de condenación y prometo de nunca juntarme con ellos y que cuanto en mí fuere, los perseguiré y las herejías que de ellos supiere, las revelaré y manifestaré a cualquier señor inquisidor de la herética pravedad y prelado de la santa madre iglesia, donde quiera que me hallare y juro y prometo que recibiré humildemente y con paciencia cualquiera penitencia que me han sido o fueren impuestas con todas mis fuerzas y poder y las cumpliré en todo y por todo, sin ir ni venir contra ello y quiero y consiento y me place que si yo en algún tiempo, lo que Dios no quiera, fuere o viniere contra las cosas susodichas y contra cualquier cosa o parte de ellas, sea en todo tenida por impenitente y me someto a la corrección y severidad de los sacros cánones para que en mí, como persona que abjura de levi, sean ejecutadas las censuras y penas en ellos contenidas y consiento que me sean dadas y las haya de sufrir cuando quiera que algo se me probara haber quebrantado de lo susodicho por mí abjurado.

Asimismo, se comunicaba el resultado del proceso a Pedro Ximénez, al mismo tiempo que se le advertía que «no trate, comunique ni cohabite con María Rodríguez Zerezo, ni disponga de su persona en el interim que no haga constar haber muerto Christóbal Muñoz Ortelano, legítimo marido de la referida María, antes de que contrajese de facto el segundo matrimonio con él, y obtenga licencia del ordinario de este obispado para poder cohabitar con ella». No se olvidaba el tribunal de exigirle el pago de 256 reales y 32 maravedíes, que se habían gastado en la manutención de María Zerezo y 80 reales que cobró el abogado que se nombró para su defensa.

\subsection{CUMPLIMIENTO DE LA PENA Y MUERTE}

El 20 de octubre de 1763, María Zerezo entraba en el Real Hospital de Santiago, a extramuros de la ciudad, para servir «a las pobres enfermas de ese hospital por espacio de cinco años», advirtiendo al administrador del hospital, don José Ruiz de Alarcón, «dar aviso al tribunal en caso de que no cumpla en su destino con su debida obligación en lo que se la mandase». Allí comenzó a servir a las pobres mujeres, que venían a refugiarse perseguidas por la soledad, pobreza y enfermedad. En medio de este ambiente sórdido y lleno de miseria, María tuvo tiempo para que «un estudiante que pasó por allí», le escribiese una carta para su esposo, Pedro 
Giménez, que fue interceptada por el Santo Oficio, llena de recuerdos y hermosos sentimientos humanos. Cuando los inquisidores le preguntaron si había escrito la carta a pesar de la prohibición que tenía de comunicarse con Pedro Giménez, confesó llanamente su autoría y de la persona que se había servido para escribirla.

No obstante, el contagio de enfermedades junto con las humillaciones y los sufrimientos psicológicos debieron de hacer mella en la persona de María, que enfermó gravemente y, al poco tiempo, murió. Ello no fue obstáculo para que los inquisidores exigieran certificación de la muerte de María Zerezo y del cumplimiento de sus obligaciones:

Como administrador del Real Hospital del Señor Santiago extramuros de la ciudad de Cuenca, certifico que según los informes que tengo del cura capellán y contador deste Real Hospital, ha cumplido la condenada el destino que se le manda por carta orden del santo tribunal dirigida a D. Joseph Ruiz de Alarcón, mi antecesor, con fecha de 20 de octubre 1763 hasta el 20 de septiembre de 1766 en que murió en este Hospital.

\section{ConClusión}

Los procesos inquisitoriales constituyen las mejores fuentes históricas para estudiar las mentalidades, antropología social, cuestiones sociales, que no nos dan los documentos oficiales relativos a la estructura administrativa del Estado. En el caso de los procesos por bigamia resultan especialmente interesantes toda vez que, al establecerse una relación humana tan íntima, se expresan los sentimientos más puros y sinceros de la persona tales como amor y odio, miedos, aspiraciones sociales, soledades personales, etc. de las mujeres y de los hombres de la época, muy semejantes a los nuestros. En una sociedad patriarcal, jerarquizada y estructurada mediante el matrimonio (contrato) como es la que ha existido en Europa durante siglos, la persona que rompía esta rígida norma se autoexcluía del sistema social y, por consiguiente, la bigamia no se debe considerar solamente como un delito religioso. La bigamia era considerada mucho más peligrosa que la prostitución porque destruía el sistema social. Las mujeres bígamas se quedaban solas, al margen de la sociedad; no resulta extraño que (como han demostrado los estudios sobre el tema) con frecuencia se les acusara también de brujas o hechiceras.

La familia del médico Pedro Giménez no hizo sino poner en práctica una idea que tenía asumida la sociedad en general de manera implícita y las instituciones de poder legalmente. Para romper el matrimonio de su hijo acusaron de bígama a la mujer con quien se había unido, utilizando para ello las amistades y sobornando testigos además de contar con «cierta simpatía» por parte de la Inquisición, institución que pensaba de la misma manera (que el matrimonio era fundamental 
en la sociedad, además de ser un sacramento de la Iglesia). Sus esfuerzos tuvieron éxito ya que consiguieron devolver a María Zerezo al lugar de donde procedía (su baja escala social, cercana a la exclusión) y para ello no dudaron en penalizar su atrevimiento de ascenso (a través del matrimonio con el médico Pedro Giménez) con el deshonor y el destierro, añadiendo de penitencia un castigo humillante, que la llevó a su muerte.

\section{BiBLIOGRAFÍA}

Alberro, Solange (1980). «El discurso inquisitorial sobre los delitos de bigamia, poligamia y solicitación». En Seis ensayos sobre el discurso colonial relativo a la comunidad doméstica. Cuadernos de Trabajo, n. ${ }^{\circ} 35$. Ciudad de México: Departamento de Investigaciones Históricas INAH, pp. 238-257.

Borromeo, Agostino (1990). «Regalismo e Inquisición bajo Carlos III: la Real Cédula de 8 de febrero de 1770». En Pablo Fernández Albaladejo et alii (dirs.), Actas del Congreso Internacional sobre Carlos III y la Ilustración. Madrid: Ministerio de Cultura, pp. 367-386.

CALDERÓN, Carlos (2001-2002). «Un siglo de transgresiones: el delito de bigamia en la Galicia del siglo XVIII según los papeles de la Inquisición». Fundación, 5, pp. 373-394.

Candau Chacón, María Luisa (2016). «Mujeres ante la justicia: bígamas en la Sevilla Moderna». Historia et ius. Rivista di storia giuridica dell'età medievale e moderna, $9<\mathrm{http} / /$ www.historiaetius.eu/uploads/5/9/4/8/5948821/candau_chacon_9. pdf> [Consulta: 09/03/2019].

CARENA, Cesare (1669). Tractatus de officio sanctissimae inquisitionis et modo procedendi in causis fidei. Lugduni: Laurent Anisson.

Castañeda, Paulino y Pilar Hernández Aparicio (1985). «Los delitos de bigamia en la Inquisición de Lima». Missionalia Hispánica, n. ${ }^{\circ}$ 122, pp. 241-273.

Collantes de Terán de la Hera, María José (2017). «La mujer en el proceso inquisitorial: hechicería, bigamia y solicitación». Anuario de Historia del Derecho Español, 87, pp. 55-87.

Cortés, María Elena (1986). «No tengo más delito que el haberme casado otra vez, o de cómo la perversión no está donde se cree». En Sergio Ortega (coord.), De la santidad a la perversión o de porqué no se cumplia la ley de Dios en la sociedad novohispana. Ciudad de México: Grijalbo, pp. 165-177.

Dedieu, Jean Pierre (1981). «El modelo sexual: la defensa del matrimonio cristiano». En Bartolomé Bennassar (coord.), La Inquisición española: poder politico y control social. Barcelona: Crítica, pp. 270-294.

Dictionarium morale et canonicum (dir. P. Palazzini). Roma: 1962, I, p. 464, v. «bigamia».

Droit Canonique. New Cork (reimp. Paris 1891).

GaCto FernÁNDEZ, Enrique (1990). «El delito de la bigamia y la Inquisición española». En Francisco Tomás y Valiente et alii, Sexo barroco y otras transgresiones premodernas. Madrid: Alianza, pp. 132-133. 
Gacto Fernández, Enrique (2013). «Imbecillitas sexus». Cuadernos de Historia del Derecho, 20, pp. 27-66.

García Gallo, Alfonso (1982). «La evolución de la condición jurídica de la mujer». Estudios de Historia del Derecho Privado. Sevilla: Universidad de Sevilla, pp. 145-166.

García SÁnchez, Justo (2010). «El Derecho Romano en un Supuesto de Bigamia, fechado en 1639». Revista jurídica da FA7: Periódico Cientifico e Cultural do Curso de Direito da Facultade 7 de Setembro, 7, pp. 145-166.

García Trasmiera, Diego (1638). De Polygamia et polyviria. Libri tres. Panhormi: Apud Decium Cyrilum.

Gil Ortego, Pedro (2015). «Frágiles y sagaces: notas sobre dolo y punición de las mujeres en la Edad Moderna». En Francisco Pacheco Caballero (ed.), Mujeres y Derecho. Una perspectiva histórico-jurídica. Barcelona: Associació Catalana d'Història del Dret «Jaume de Montjuïc», pp. 187-261.

Hevia de Bolaños, Juan de (1657). Curia Filipica donde se trata de los juizios forenses, eclesiásticos, seculares. Madrid: Viuda de Fernando Correa.

LARDIZÁBAl y URIBE, Manuel (1782). Discurso sobre las penas contrato a las leyes criminales en España para facilitar su reforma. Madrid: Joachin Ibarra.

LEA, Henry Charles (1983). Historia de la Inquisición Española. Madrid: Fundación Universitaria Española.

Levack, Brian P. (1995). La caza de las brujas en la Europa Moderna. Madrid: Alianza.

Manrique, Alonso (1667). Compilación de las Instrucciones del Oficio de la Santa Inquisición. Madrid: Diego García de la Carrera.

MolinA, Fernanda (2017). «Casadas dos veces. Mujeres e inquisidores ante el delito de bigamia femenina en el Virreinato del Perú (siglos XVI-XVII)». Memoria Americana. Cuadernos de Etnohistoria, 25/1, pp. 31-46.

Moreno Florido, María S. (2014). «Mujer y bigamia: ¿amor o delito? Análisis desde la perspectiva del Santo Oficio en Canarias (1598-1621)». En Coloquios Casa de Colón. Gran Canaria: Cabildo de Gran Canaria/Cultura, pp. 1.330-1.336<https:// www.google.com/url?sa $=\mathrm{t} \& \mathrm{rct}=\mathrm{j} \& \mathrm{q}=\&$ esrc $=\mathrm{s} \&$ source $=$ web\& $\mathrm{cd}=1 \& \mathrm{ved}=2 \mathrm{ahUK}$ EwijuKG6vazjAhUK-hQKHfTzC5UQFjAAegQIARAC\&url=http\%3A\%2F\%2F coloquioscanariasamerica.casadecolon.com $\% 2$ Findex.php $\% 2 \mathrm{FCHCA} \% 2 \mathrm{Farticle}$ \%2Fview\%2F8224\%2F7278\&usg=AOvVaw3QXSxdbnUNFARtVAOPNgD6> [Consulta: 12/05/2019].

Ots CAPdequi, José María (1930). «El sexo como circunstancia modificativa de la capacidad jurídica en nuestra legislación de Indias». Anuario de Historia del Derecho Español, 7, pp. 311-380.

Pascua SÁnchez, María José de la (1998). Mujeres solas: historias de amor y abandono en el mundo hispánico. Málaga: Servicio de Publicaciones/Centro de Ediciones de la Diputación de Málaga.

PoskA, Allison M. (2000). «Cuando se las juzga por bigamia. Las mujeres gallegas y el Santo Oficio». En Mary Giles (ed.), Mujeres en la Inquisición. La persecución del Santo Oficio en España y el Nuevo Mundo. Barcelona: Ediciones Martínez Roca, pp. 232-252. 
SARrión Mora, Adelina (2003). Beatas y endemoniadas. Mujeres heterodoxas ante la Inquisición, siglos XVI-XIX. Madrid: Alianza.

Torres Aguilar, Manuel (1997). «Algunos aspectos del delito de bigamia en la Inquisición de Indias». Revista de la Inquisición, 6, pp. 117-138.

Torres Aguilar, Manuel (1997). «El delito de bigamia: estudio general y especial perspectiva en el Tribunal de la Inquisición de Sevilla en el siglo XVIII». En Enrique Gacto Fernández (ed.), El centinela de la fe. Estudios jurídicos sobre la Inquisición de Sevilla en el siglo XVIII. Sevilla: Universidad de Sevilla, pp. 173-232.

Valton, Emilie (1910). «Bigamie». En Dictionnaire de Théologie Catholique. Paris: [s.e.], II, pp. 881-885.

VASALlo, Jaqueline (1999-2000). «El sexo como circunstancia modificatoria de la responsabilidad penal en la Setena Partida de Alfonso X el Sabio». Anuario de la Facultad de Derecho y Ciencias Sociales de la Universidad de Córdoba (Argentina), 5, pp. 489-496.

Recibido: $13 / 05 / 2019$

Aceptado: 27/07/2019 
LA INQUISICIÓN CONTRA LA BIGAMIA: EN DEFENSA DEL ORDEN SOCIAL

RESUMEN: Además de los sentimientos, mentalidad y circunstancias antropológicas y sociales, que se descubren en un proceso inquisitorial por bigamia, la acusación de bigamia, ante todo, llevaba consigo la exclusión social, si se tiene en cuenta que el matrimonio era el elemento que estructuraba la sociedad de Occidente. Una familia manchega lo entendió a la perfección y utilizó la Inquisición para acusar de este delito a una mujer, que se había casado con su hijo en segundas nupcias, para segregarla socialmente e impedir que se incorporara a su nivel social, que era superior.

PALABRAS Clave: Inquisición, mujer, bigamia.

THE INQUisition agaINST Bigamia: IN DEFENSE OF THE SOCIAL ORDER

ABstract: In addition to the feelings, mentality and anthropological and social circumstances, which are discovered in an inquisitorial process by bigamy, the accusation of bigamy, above all, entailed social exclusion, if one takes into account that marriage was the element that structured the society of the West. One family in La Mancha understood this perfectly and used the Inquisition to accuse a woman who had married her son in second marriages, to segregate her socially and prevent her from joining his social level, which was superior.

KEYwORDS: Inquisition, woman, bigamy. 